\title{
Estabilidade da polpa de morango atomizada utilizando diferentes agentes carreadores
}

Stability of spray-dryed strawberry pulp produced with different carrier agents

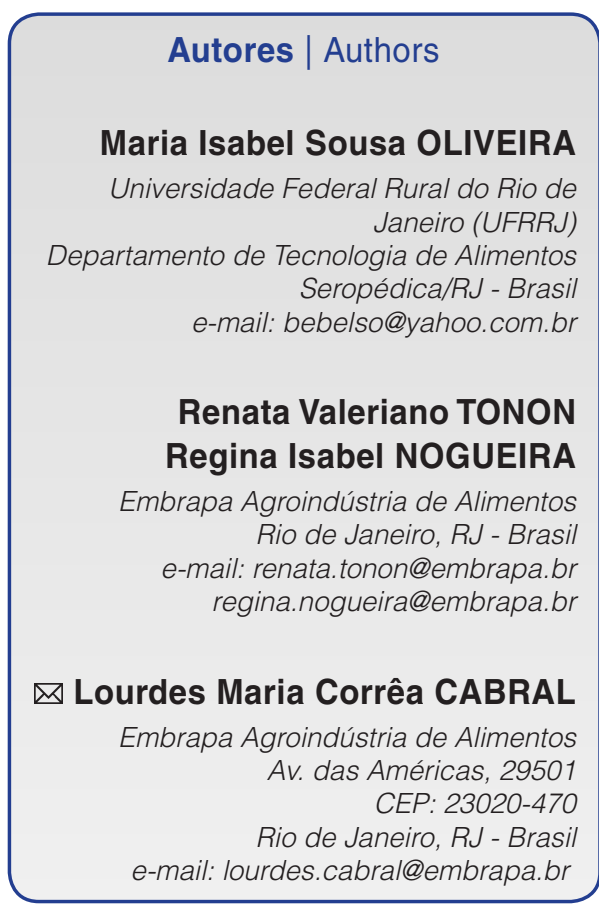

$\triangle$ Autor Correspondente / Corresponding Author

Recebido / Received: 27/06/2013 Aprovado / Approved: 14/11/2013 Publicado / Published: dez./2013

\section{Resumo}

Este trabalho teve por objetivo avaliar o efeito de diferentes agentes carreadores (Maltodextrina 5DE, Maltodextrina 10DE, Goma arábica e Capsul ${ }^{\circledR}$ ) nas características físico-químicas (umidade, densidade, solubilidade, teor de antocianinas e atividade antioxidante) da polpa de morango desidratada por atomização e armazenada à temperatura ambiente por 90 dias. A utilização dos diferentes agentes carreadores resultou em pós com valores de densidade aparente entre 0,40 e $0,52 \mathrm{~g} / \mathrm{cm}^{3}$ e umidade menor do que $2,5 \%$. Todas as amostras foram altamente solúveis, mas os pós obtidos com a Maltodextrina 5DE e com a Goma arábica apresentaram menor higroscopicidade. As isotermas de sorção obtidas foram do tipo III e o modelo de GAB foi o que melhor se ajustou aos dados experimentais. A amostra produzida com goma arábica apresentou a maior concentração de antocianinas e, consequentemente, maior valor de atividade antioxidante, tanto imediatamente após a secagem como ao longo de 90 dias de armazenamento. Os resultados obtidos indicaram que a goma arábica foi o agente carreador mais adequado para a produção de polpa de morango em pó.

Palavras-chave: Isotermas de sorção; atividade antioxidante; antocianinas.

\section{Summary}

This study aimed to evaluate the effect of different carrier agents (5DE Maltodextrin, 10DE Maltodextrin, gum Arabic and Capsul ${ }^{\circledR}$ ) on the physicochemical characteristics (moisture content, density, solubility, total anthocyanins and antioxidant activity) of strawberry pulp processed by spray drying and stored at room temperature for 90 days. The use of different carrier agents resulted in powders with bulk densities ranging from 0.40 to $0.52 \mathrm{~g} / \mathrm{cm}^{3}$ and moisture contents below $2.5 \%$. All the samples were highly soluble, but the powders obtained with 5DE Maltodextrin and gum Arabic were less hygroscopic. The sorption isotherms were of type III and the GAB model was the model that best fitted the experimental data. The powder produced with gum Arabic had the highest anthocyanin content and consequently the greatest antioxidant activity value, both immediately after the drying process and during the storage period. The results obtained showed that gum Arabic was the most suitable carrier agent for the production of strawberry pulp powder.

Key words: Sorption isotherms; antioxidant activity; anthocyanin. 


\section{Introdução}

A produção de morango no Brasil vem crescendo em função da grande demanda dos consumidores e das agroindústrias por esta fruta, que, além de nutritiva, é um ingrediente em diversas preparações, tais como caldas, iogurtes, bebidas, biscoitos e sorvetes, entre outras. No entanto, além de ter uma produção sazonal, o morango é uma fruta muito delicada, com alta taxa respiratória, sendo, por isso, altamente perecível (ROCHA et al., 2008).

Uma aplicação de crescente interesse industrial é a produção de polpas e sucos de frutas em pó por atomização (FERRARl et al., 2012; TONON et al., 2010; SILVA et al., 2008). Com esta técnica, é possível obter um produto com baixa atividade de água e, portanto, microbiologicamente mais estável, que pode ser armazenado à temperatura ambiente, além de permitir que substâncias sensíveis ao calor, à luz ou à oxidação sejam protegidas. O produto seco apresenta, como vantagens, o aumento da sua vida útil, a redução do volume e, consequentemente, dos custos de transporte e armazenamento, e sua maior disponibilidade ao longo do ano (YOUSEFI et al., 2011; AZEREDO, 2005), mas demanda certos cuidados, como o uso de embalagens impermeáveis à umidade, por exemplo.

Em geral, sucos de frutas contêm alta concentração de açúcar, o que resulta em pós com baixa temperatura de transição vítrea e alta higroscopicidade e pegajosidade, acarretando problemas, como adesão às paredes do secador, aglomeração e dificuldades de manuseio. A adição de materiais poliméricos como agentes carreadores ao suco de fruta aumenta a temperatura de transição vítrea do pó formado, minimizando problemas de aderência e manipulação (BHANDARI et al. 1997; ROOS e KAREL, 1991), além de aumentar o rendimento do processo e a estabilidade do produto em condições ambientais, devido à formação de um "filme" protetor.

A maltodextrina é um produto da hidrólise do amido e representa o agente carreador mais comum na secagem de sucos de frutas, por ser um material inodoro, de baixo custo e possuir baixa viscosidade em altas concentrações. A goma arábica é um exsudato da seiva da árvore do gênero Acácia, sendo a única entre as gomas alimentícias com alta solubilidade e baixa viscosidade em solução, e, assim como a maltodextrina, também vem sendo utilizada na secagem de sucos de frutas (FERRARI et al., 2012; TONON et al., 2010; CANO-CHAUCA et al., 2005). Os amidos modificados também vêm sendo utilizados na encapsulação de compostos bioativos e substâncias voláteis, conferindo boa proteção e estabilidade (CHARVE e REINECCIUS, 2009; BARANAUSKIENÉ et al., 2007).

Diante do exposto, este trabalho teve como objetivo estudar o efeito de diferentes agentes carreadores nas características físicas (umidade, densidade, higroscopicidade e solubilidade) e químicas (teor de antocianinas e atividade antioxidante) da polpa de morango desidratada por atomização e armazenada à temperatura ambiente durante 90 dias.

\section{Material e métodos}

\subsection{Matéria-prima}

Morangos da cultivar Oso Grande foram adquiridos no mercado local do Rio de Janeiro-RJ. Os morangos foram selecionados (descartando-se os que apresentassem injúrias mecânicas e infecção por fungos), higienizados (imersos em solução de hipoclorito de sódio a 20 ppm, durante 10 minutos) e então despolpados em uma despolpadeira Bonina 0,25 df (Itametal, Itabuna, Bahia, Brasil), com uma peneira de 0,6 mm. A polpa foi posteriormente filtrada em uma malha com abertura média dos poros de $150 \mu \mathrm{m}$, para diminuir o teor de sólidos em suspensão, de modo a facilitar a sua passagem pelo bico atomizador. A polpa refinada foi congelada à temperatura de $-18{ }^{\circ} \mathrm{C}$, sendo descongelada em temperatura de refrigeração $\left(4^{\circ} \mathrm{C}\right)$, de acordo com a quantidade necessária para cada ensaio.

\subsection{Agentes carreadores}

Foram utilizados como agentes carreadores: maltodextrinas GLOBE $1905^{\circledR}$ de 5 DE e MOR-REX $1910^{\circledR}$ de 10 DE (Corn Products, São Paulo, Brasil), goma arábica Instantgum BA ${ }^{\circledast}$ (Colloides Naturels, São Paulo, Brasil) e o amido modificado com anidrido n-octanil succínico, Capsul TA ${ }^{\circledast}$ (National Starch, São Paulo, Brasil).

\subsection{Secagem por atomização}

Cada formulação, na proporção de 1:2 (sólidos da polpa de morango: agente carreador), foi homogeneizada até a completa solubilização, utilizando-se cerca de $300 \mathrm{~g}$ de polpa em cada ensaio. Em seguida, a mistura foi submetida à secagem por atomização em um mini spray dryer Buchi Modelo B-190 (Flawil, Suíça), com temperaturas do ar de entrada e saída de $180{ }^{\circ} \mathrm{C}$ e 90 ${ }^{\circ} \mathrm{C}$ (definidas em ensaios preliminares), respectivamente; pressão do ar comprimido de 7 bar; vazão média do ar secagem de 700 L/h, e vazão média de alimentação de $15 \mathrm{~mL} / \mathrm{min}$. Para o estudo da estabilidade, as amostras foram estocadas em embalagens flexíveis de alumínio revestidas com polietileno e colocadas em dessecadores contendo sílica gel, à temperatura ambiente $\left(25 \pm 2{ }^{\circ} \mathrm{C}\right)$, durante 90 dias, sendo avaliadas periodicamente, a cada 15 dias, em relação aos teores de antocianinas totais e atividade antioxidante. 


\subsection{Métodos analíticos}

\subsubsection{Densidade aparente}

A densidade aparente $\left(\rho_{a p}\right)$ foi determinada transferindo-se $1 \mathrm{~g}$ do pó de morango atomizado para uma proveta graduada de $10 \mathrm{~mL}$, sendo calculada como a relação entre a massa de pó e o volume ocupado (GOULA e ADAMOPOULOS, 2004).

\subsubsection{Solubilidade}

A solubilidade foi determinada pelo método descrito por Eastman e Moore (1984), modificado por Cano-Chauca et al. (2005), que consiste na adição de $0,5 \mathrm{~g}$ de amostra em um recipiente contendo $50 \mathrm{~mL}$ de água destilada, sob agitação magnética de 1.000 rpm, por 5 minutos, seguida por centrifugação a 4.500 rpm, por 5 minutos. Uma alíquota de $12,5 \mathrm{~mL}$ do sobrenadante foi levada à estufa a $105^{\circ} \mathrm{C}$, até peso constante, e a solubilidade foi calculada pela diferença de peso, de acordo com a Equação 1:

$$
\text { Solubilidade }(\%)=\frac{\text { Massa de pó no sobrenadante }}{\text { Massa de pó total }} \times 100
$$

\subsubsection{Isotermas de sorção}

A umidade de equilíbrio das amostras de morango em pó foi determinada pelo método gravimétrico estático (GAL, 1981), utilizando-se oito soluções salinas saturadas em água destilada [ $\mathrm{LiCl}, \mathrm{CH}_{3} \mathrm{COOK}, \mathrm{MgCl}_{2}, \mathrm{~K}_{2} \mathrm{CO}_{3}$, $\mathrm{Mg}\left(\mathrm{NO}_{3}\right)_{2}, \mathrm{KI}, \mathrm{NaCl}$ e $\mathrm{KCl}$, resultando em umidades relativas de $11,3 \%, 22,6 \%, 32,8 \%, 43,2 \%, 52,9 \%$, $68,9 \%, 75,3 \%$ e $84,3 \%$, respectivamente (GREENSPAN, 1977).

Os modelos de BET (três parâmetros) e GAB (Tabela 1) foram ajustados aos dados experimentais, por apresentarem certo significado físico relacionado ao processo de sorção de água, quando comparados aos modelos empíricos biparamétricos mais comumente utilizados.

Tabela 1. Modelos matemáticos utilizados para o ajuste de isotermas de sorção do pó.

$\begin{array}{ll}\text { Modelo } & \text { Equação } \\ \text { BET } & X_{e}=\frac{X_{m} C_{B E T} a_{w}[1-(N+1)]\left(a_{w}\right)^{N}+N\left(a_{w}\right)^{N+1}}{\left(1-a_{w}\right)\left[1-\left(1-C_{B E T}\right) a_{w}-C_{B E T}\left(a_{w}\right)^{N+1}\right]} \\ \text { GAB } & X_{e}=\frac{X_{m} C_{G A B} K_{G A B} a_{w}}{\left[\left(1-K_{G A B} a_{w}\right)\left(1-K_{G A B} a_{w}+C_{G A B} K_{G A B} a_{w}\right)\right]}\end{array}$

$X_{e}$ : umidade de equilíbrio ( $g$ água/g sólidos secos); $X_{m}$ : umidade na monocamada molecular (g água/g sólidos secos); Ni: número de camadas moleculares; $C_{B E T}, C_{G A B}, K_{G A B}, K_{A}, K_{B}, n_{A}$ e $n_{B}$ : constantes.
Os parâmetros destes modelos foram determinados por análise de regressão não linear dos dados experimentais, com o auxílio da ferramenta Solver do software Microsoft Excel (Microsoft, Redmond, EUA). Os parâmetros de escolha dos melhores ajustes foram o coeficiente de determinação $\left(R^{2}\right)$ e o desvio percentual médio entre os valores experimentais e os preditos ( $\mathrm{P} \%)$.

$P(\%)=\frac{100}{N} \sum_{i=1}^{N} \frac{\left|V_{E}-V_{P}\right|}{V_{E}}$

em que: $V_{E}=$ valor experimental; $V_{P}=$ valor predito pelo modelo.

\subsubsection{Análises químicas}

A determinação de umidade, $\mathrm{pH}$, acidez e teor de sólidos solúveis e totais da polpa de morango foi realizada segundo as metodologias do Instituto Adolfo Lutz (IAL, 2008).

O teor de antocianinas totais foi determinado pelo método espectrofotométrico do $\mathrm{pH}$ diferencial descrito por Giusti e Wrolstad (2001), considerando a cianidina-3-glucosídeo como antocianina padrão. A atividade antioxidante foi determinada segundo o método espectrofotométrico baseado na descoloração do radical livre $\mathrm{ABTS}^{+}$(ácido 2,2'-azino-bis-3-etilbenzotiazolina6-sulfônico sal diamônio 98\% pureza), de acordo com Re et al. (1999). Os resultados foram expressos como TEAC (Capacidade Antioxidante Equivalente ao Trolox) em $\mu \mathrm{mol} / \mathrm{g}$ de amostra.

\subsection{Análise estatística}

Todas as análises foram realizadas em triplicata e os resultados foram analisados estatisticamente através do Teste de Tukey, no nível de $5 \%$ de significância ( $p \leq$ $0,05)$, utilizando o programa computacional ASSISTAT versão 7.6 BETA (2012).

\section{Resultados e discussão}

\subsection{Caracterização da polpa de morango}

A caracterização físico-química da polpa de morango utilizada nos ensaios pode ser observada na Tabela 2.

A concentração de antocianinas totais e o valor da atividade antioxidante da polpa de morango são similares aos reportados por Kuskoski et al. (2006), de 23,7 mg/100g e 9,2 $\mu \mathrm{mol}$ Trolox/g, respectivamente, e por Zheng et al. (2007), de 20,07 mg/100g e 10,63 $\mu \mathrm{mol}$ Trolox/g, respectivamente.

A composição de sólidos totais presentes na polpa de morango é majoritariamente constituída de açúcares ( $6^{\circ}$ Brix, em $6,79 \%$ de sólidos totais), o que justifica a 
Tabela 2. Caracterização físico-química da polpa de morango filtrada.

\begin{tabular}{lc}
\multicolumn{1}{c}{ Análises } & Valores \\
\hline $\mathrm{pH}$ & $3,55 \pm 0,01$ \\
Acidez Total Titulável & $0,84 \pm 0,06$ \\
(g ácido cítrico/100 $\mathrm{mL}$ de polpa) & \\
Sólidos Solúveis Totais ( ${ }^{\circ}$ Brix) & $6,00 \pm 0,05$ \\
Sólidos Totais (g/100 g de polpa) & $6,79 \pm 0,09$ \\
Antocianinas Totais (mg/100 g de polpa) & $19,33 \pm 0,61$ \\
Atividade Antioxidante (TEAC) & $13,03 \pm 0,36$ \\
( $\mu$ mol Trolox/g polpa) & \\
\hline
\end{tabular}

adição de agentes carreadores antes da secagem por atomização, evitando problemas, como pegajosidade e empastamento, tanto no interior do equipamento como no produto processado.

\subsection{Solubilidade e densidade aparente}

A Tabela 3 apresenta os valores de solubilidade e densidade aparente do pó da polpa de morango atomizada com diferentes agentes carreadores.

Conforme esperado, todas as amostras apresentaram alta solubilidade, uma vez que estes agentes carreadores caracterizam-se por sua alta solubilidade em água. As solubilidades das amostras produzidas com o Capsul ${ }^{\circledR}$ e as maltodextrinas foram estatisticamente iguais entre si e ligeiramente superiores à observada para a amostra produzida com goma arábica. Cano-Chauca et al. (2005) observaram valores de solubilidade superiores a $90 \%$ no suco de manga atomizado com maltodextrina $10 \mathrm{DE}$ e goma arábica. A alta solubilidade dos pós obtidos revela seu potencial como ingrediente em produtos alimentícios, como bebidas e preparados de sobremesas instantâneos.

Os pós apresentaram valores significativamente diferentes de densidade aparente, na mesma ordem dos observados por Ferrari et al. (2012), que caracterizaram polpa de amora encapsulada com maltodextrina e com goma arábica, apresentando valores de densidade aparente de 0,409 e 0,424 $\mathrm{g} / \mathrm{cm}^{3}$, respectivamente. A maltodextrina é um polissacarídeo obtido pela hidrólise do amido. Quanto mais hidrolisado o amido, menor sua densidade, uma vez que as ligações rompidas resultam em cadeias menores e mais leves.

Dessa forma, a amostra produzida com maltodextrina 5DE apresentou densidade estatisticamente maior do que a produzida com maltodextrina 10DE. A goma arábica é constituída por cadeias de polissacarídeos (ácido D-glucorônico, L-ramnose, D-galactose, L-arabinose) e proteína de alta massa molar (BE MILLER e WHISTLER, 1996), o que pode justificar sua maior densidade em relação às maltodextrinas. O Capsul ${ }^{\circledR}$, amido
Tabela 3. Solubilidade e densidade das partículas produzidas com diferentes agentes carreadores.

\begin{tabular}{lcc}
\multicolumn{1}{c}{$\begin{array}{c}\text { Agentes } \\
\text { Carreadores }\end{array}$} & $\begin{array}{c}\text { Solubilidade } \\
\mathbf{( g / 1 0 0 ~} \mathbf{~ g})\end{array}$ & $\begin{array}{c}\text { Densidade } \\
\text { aparente }\left(\mathbf{g} / \mathbf{c m}^{3}\right)\end{array}$ \\
\hline Maltodextrina 5DE & $90,37 \pm 1,27^{\mathrm{ab}}$ & $0,41 \pm 0,002^{\mathrm{c}}$ \\
Maltodextrina 10DE & $91,01 \pm 1,74^{\mathrm{a}}$ & $0,40 \pm 0,004^{\mathrm{d}}$ \\
Goma Arábica $_{\text {Capsul }^{\circledR}}^{87,15 \pm 1,44^{\mathrm{b}}}$ & $0,47 \pm 0,003^{\mathrm{b}}$ \\
\hline
\end{tabular}

Letras diferentes na mesma coluna indicam diferença estatisticamente significativa entre as amostras produzidas com diferentes agentes carreadores $(p \leq 0,05)$.

modificado derivado de milho ceroso, é constituído quase que totalmente por amilopectina e apresenta um grau de dextrose equivalente (DE) menor do que dois (PARAMITA et al., 2012; KUNTZ, 1997), o que poderia explicar a maior densidade aparente do pó de morango obtido com este agente carreador.

\subsection{Isotermas de sorção}

Os valores da umidade de equilíbrio $\left(X_{e}\right)$ aumentaram com o aumento da atividade de água (Tabela 4), o que era esperado, uma vez que ambientes com maior umidade relativa tendem a promover maior adsorção de água pelo material exposto, até que se atinja o equilíbrio termodinâmico.

A umidade das amostras armazenadas em diferentes atividades de água variou entre 0,007 e 0,383 g/g matéria seca (Tabela 4), valores que representam, em base úmida, umidades de 0,7\% e 27,7\%, respectivamente. Foi observado colapso nas amostras armazenadas em atividades de água superiores a 0,432, quando os pós começaram a formar aglomerados duros e escuros. 0 aumento da umidade relativa resultou em estruturas mais rígidas e as atividades de água mais altas fizeram com que os pós ficassem com a aparência de um líquido muito pegajoso, como consequência da liquefação, que acarreta uma solubilização das frações de baixo peso molecular (AGUILERA et al., 1995).

A Tabela 5 apresenta os valores dos parâmetros estimados pelos modelos de BET e GAB, para o ajuste das isotermas de sorção da polpa de morango atomizada, assim como o coeficiente de determinação $\left(R^{2}\right)$ e o desvio percentual médio $(P \%)$.

Segundo Lomauro et al. (1985), um modelo apresenta um bom ajuste quando o valor do $R^{2}$ está próximo da unidade e o valor do ( $P \%)$ é inferior a $10 \%$. Portanto, no presente trabalho, ambos os modelos tiveram um excelente ajuste aos dados experimentais de umidade de equilíbrio.

O modelo de GAB foi o que apresentou os menores valores de $P(\%)$ e os maiores valores de $R^{2}$, sendo selecionado para representar as isotermas de sorção 
Tabela 4. Valores experimentais da umidade de equilíbrio $\left(X_{e}\right)$ nas diferentes atividades de água $\left(a_{w}\right)$ para as amostras produzidas com diferentes tipos de agentes carreadores.

\begin{tabular}{ccccc}
$\mathbf{a}_{\mathbf{w}}$ & MD5 & Umidade de Equilíbrio $-\mathbf{X}_{\mathbf{e}}$ (g/g matéria seca) & CAP \\
0,112 & $0,007 \pm 0,000$ & $0,008 \pm 0,000$ & $0,007 \pm 0,001$ & $0,007 \pm 0,001$ \\
0,226 & $0,016 \pm 0,000$ & $0,014 \pm 0,000$ & $0,017 \pm 0,000$ & $0,022 \pm 0,002$ \\
0,328 & $0,025 \pm 0,000$ & $0,032 \pm 0,000$ & $0,024 \pm 0,001$ & $0,041 \pm 0,006$ \\
0,432 & $0,040 \pm 0,000$ & $0,055 \pm 0,001$ & $0,049 \pm 0,001$ & $0,066 \pm 0,000$ \\
0,529 & $0,070 \pm 0,001$ & $0,088 \pm 0,001$ & $0,077 \pm 0,001$ & $0,103 \pm 0,001$ \\
0,689 & $0,133 \pm 0,000$ & $0,159 \pm 0,000$ & $0,150 \pm 0,000$ & $0,193 \pm 0,000$ \\
0,753 & $0,175 \pm 0,000$ & $0,202 \pm 0,000$ & $0,193 \pm 0,000$ & $0,249 \pm 0,001$ \\
0,843 & $0,292 \pm 0,000$ & $0,328 \pm 0,001$ & $0,321 \pm 0,001$ & $0,383 \pm 0,001$ \\
\hline
\end{tabular}

MD5 = Maltodextrina 5DE; MD10 = Maltodextrina 10DE; GA = Goma Arábica; CAP = Amido Modificado, Capsul ${ }^{\oplus}$.

Tabela 5. Parâmetros de ajuste das isotermas de sorção de polpa de morango em pó produzida com diferentes agentes carreadores. $\left(\right.$ MD5 $=$ Maltodextrina 5DE; MD10 = Maltodextrina 10DE; GA = Goma Arábica; CAP = Amido Modificado, Capsul $\left.^{\circledR}\right)$.

\begin{tabular}{|c|c|c|c|c|c|}
\hline \multirow{2}{*}{ Modelos } & \multirow{2}{*}{ Parâmetros } & \multicolumn{4}{|c|}{ Agentes Carreadores } \\
\hline & & MD5 & MD10 & GA & CAP \\
\hline \multirow{5}{*}{ BET } & $X_{m}$ & 0,053 & 0,058 & 0,058 & 0,068 \\
\hline & $C_{B E T}$ & 1,259 & 1,695 & 1,317 & 1,923 \\
\hline & $N$ & 125,00 & 125,50 & 104,64 & 134,26 \\
\hline & $P(\%)$ & 1,17 & 1,87 & 1,44 & 2,01 \\
\hline & $R^{2}$ & 0,998 & 0,995 & 0,997 & 0,994 \\
\hline \multirow{5}{*}{ GAB } & $X_{m}$ & 0,091 & 0,080 & 0,080 & 0,215 \\
\hline & $C_{G A B}$ & 0,616 & 1,241 & 1,000 & 0,452 \\
\hline & $K_{G A B}$ & 0,931 & 0,946 & 0,940 & 0,836 \\
\hline & $P(\%)$ & 0,57 & 1,85 & 1,57 & 0,83 \\
\hline & $R^{2}$ & 0,999 & 0,999 & 0,999 & 1,000 \\
\hline
\end{tabular}

$X_{\mathrm{e}}$ : umidade de equilíbrio ( $\mathrm{g}$ água/g sólidos secos); $X_{m}$ : umidade na monocamada molecular (g água/g sólidos secos); $N$ : número de camadas moleculares; $C_{B E T}, C_{G A B}, K_{G A B}$ : constantes; $P \%$ : desvio percentual médio; $R^{2}$ : coeficiente de determinação.

da polpa de morango em pó para os diferentes agentes carreadores (Figura 1). O modelo de GAB foi também o que melhor se ajustou aos dados experimentais de isotermas de sorção de polpa de caju (MOURA et al., 2004), sapoti liofilizado (OLIVEIRA et al., 2011), polpa de manga (PAGLARINI et al., 2013) e cupuaçu em pó (SILVA et al., 2008).

A equação de BET é bastante utilizada em alimentos e baseia-se no conceito de adsorção de água na monocamada molecular. Já a equação de GAB representa uma extensão do modelo de BET, o que pode explicar seu melhor ajuste, tendo sido introduzida para padronizar a descrição e a comparação do material biológico. Ambos os modelos calculam o valor de $X_{m}$, que representa a quantidade de água fortemente adsorvida aos sítios específicos na superfície do alimento e é considerado como o valor ótimo para assegurar sua estabilidade (FENNEMA, 1996).

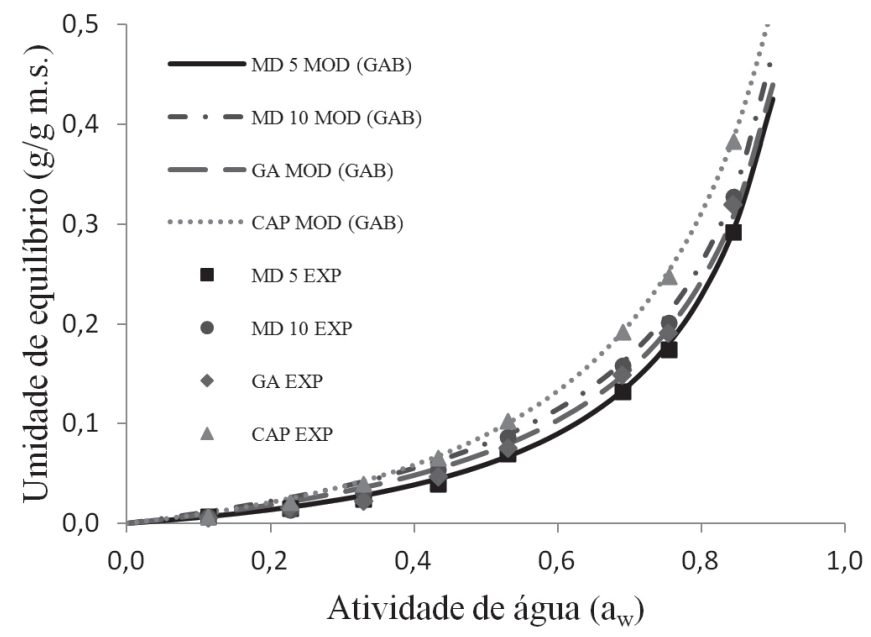

Figura 1. Isotermas de sorção a $25^{\circ} \mathrm{C}$ da polpa de morango em pó produzida com diferentes agentes carreadores, ajustadas pelo modelo de GAB. (MD5 = Maltodextrina 5DE; MD10 = Maltodextrina 10DE; GA = Goma Arábica; CAP = Amido Modificado, Capsul ${ }^{\circledR} ; \mathrm{MOD}=$ modelo; EXP = experimental). 
As isotermas de sorção de alimentos que possuem elevadas concentrações de açúcar, como a maior parte das frutas, geralmente se assemelham às isotermas do tipo II e do tipo III. De acordo com a classificação de Brunauer (FAGERLUND, 1973), as curvas obtidas para polpa de morango em pó apresentaram formato do tipo III. Este tipo de curva também foi observado por Klewicki et al. (2009), em maçã, amarena e cassis em pó, e por Silva et al. (2008), em açaí e cupuaçu em pó.

De acordo com a Figura 1, a amostra produzida com Maltodextrina 5DE foi a menos higroscópica, seguida pelas produzidas com Goma Arábica, Maltodextrina 10DE e Capsul ${ }^{\circledR}$. Essa diferença na adsorção de água pode ser explicada pela estrutura química de cada agente carreador. A maltodextrina 5DE é menos hidrolisada que a maltodextrina $10 \mathrm{DE}$, possuindo menos grupos hidrofílicos e maior peso molecular; consequentemente, adsorve menos água (ERSUS e YURDAGEL, 2007; CAI e CORKE, 2000). A goma arábica, por sua vez, também apresenta um grande número de ramificações com grupos hidrofilicos em sua estrutura (BE MILLER e WHISTLER, 1996), o que pode ser responsável pela adsorção de água do ambiente.

\subsection{Estabilidade ao armazenamento}

As antocianinas são pigmentos muito instáveis, que podem ser degradadas sob ação de oxigênio, temperatura e $\mathrm{pH}$, ou até mesmo destruídas durante o processamento e o armazenamento dos alimentos. Portanto, representa um parâmetro adequado para se avaliar a estabilidade da polpa de morango atomizada ao armazenamento.

Os pós obtidos com goma arábica apresentaram o maior teor de antocianinas totais após o processo de secagem, seguidos pelas amostras produzidas com Maltodextrina 10DE e Capsul ${ }^{\circledR}$, cujo teor de antocianinas foi estatisticamente menor e não apresentou diferença significativa entre esses dois materiais. O menor teor de antocianinas foi observado nas partículas produzidas com Maltodextrina 5DE (Tabela 6).

Tabela 6. Análises químicas dos pós produzidos com diferentes agentes carreadores, logo após o processamento.

\begin{tabular}{lcc}
\multicolumn{1}{c}{$\begin{array}{c}\text { Agentes } \\
\text { carreadores }\end{array}$} & $\begin{array}{c}\text { Antocianinas } \\
\text { Totais } \\
(\mathbf{m g} / \mathbf{1 0 0} \mathbf{~ g})\end{array}$ & $\begin{array}{c}\text { Atividade } \\
\text { Antioxidante } \\
(\mathbf{m g} / \mathbf{1 0 0} \mathbf{~ g})\end{array}$ \\
\hline Maltodextrina 5DE & $81,05 \pm 1,12^{\mathrm{c}}$ & $48,69 \pm 0,65^{\mathrm{c}}$ \\
Maltodextrina 10DE & $84,24 \pm 1,03^{\mathrm{b}}$ & $50,17 \pm 0,77^{\mathrm{b}}$ \\
Goma Arábica & $90,42 \pm 2,15^{\mathrm{a}}$ & $57,73 \pm 1,31^{\mathrm{a}}$ \\
Capsul $^{\circledR}$ & $85,12 \pm 1,22^{\mathrm{b}}$ & $45,17 \pm 1,29^{\mathrm{d}}$ \\
\hline
\end{tabular}

Letras diferentes na mesma coluna indicam diferença estatisticamente significativa entre as amostras produzidas com diferentes agentes carreadores $(p \leq 0,05)$.
A amostra produzida com Goma Arábica apresentou uma densidade aparente elevada e solubilidade ligeiramente inferior às demais. A densidade aparente considera o volume dos espaços presentes entre as partículas e, dessa forma, quanto maior a densidade aparente, menor é a quantidade de ar ocluso. Dessa forma, a maior densidade das partículas produzidas com goma arábica pode ter ocasionado uma menor taxa de difusão do oxigênio (DESOBRY et al., 1997), retardando, assim, a oxidação das antocianinas. Comportamento similar foi verificado para o valor da atividade antioxidante.

Na Figura 2, observa-se o teor de antocianinas totais durante $\mathrm{o}$ armazenamento das amostras atomizadas com diferentes agentes carreadores. Não houve influência do tempo de armazenamento nos resultados, independentemente do agente carreador usado, indicando que todos os materiais conferiram boa estabilidade às antocianinas presentes na polpa de morango, além da possível proteção conferida pela própria embalagem. As amostras produzidas com diferentes agentes carreadores, por sua vez, apresentaram diferença estatística entre si, em todos os tempos de armazenamento avaliados, sendo que a goma arábica foi o agente carreador mais eficiente na proteção deste pigmento.

Letras minúsculas diferentes indicam diferença estatisticamente significativa para o mesmo agente carreador nos diferentes dias. Letras maiúsculas diferentes indicam diferença estatisticamente significativa entre diferentes materiais para o mesmo dia.

Da mesma forma que se observou para as antocianinas, não houve influência estatisticamente significativa do tempo sobre a atividade antioxidante das amostras produzidas com o mesmo agente carreador, ao longo dos 90 dias de armazenamento (Figura 3). As amostras produzidas com diferentes agentes carreadores,

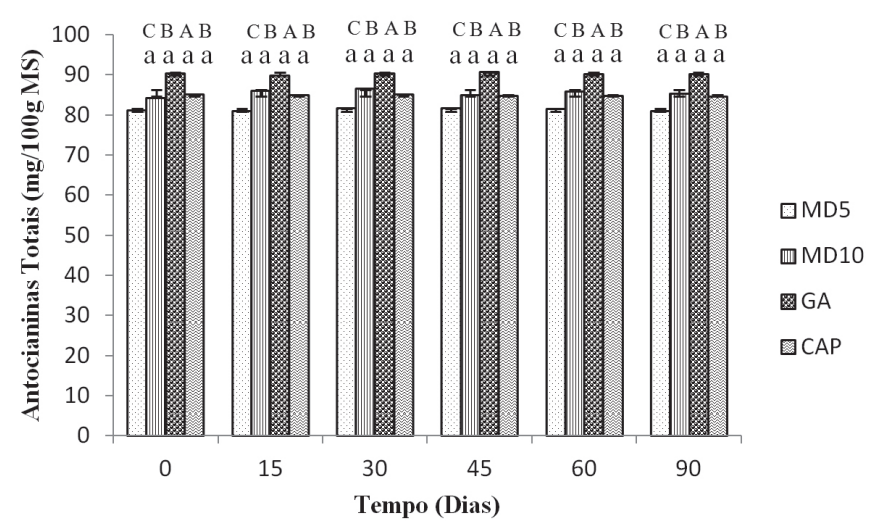

Figura 2. Evolução do teor de antocianinas totais para amostras de morango em pó com os diferentes agentes carreadores ao longo do armazenamento a $25^{\circ} \mathrm{C}$. (MD5 = Maltodextrina 5DE; MD10 = Maltodextrina 10DE; GA = Goma Arábica; CAP = Amido Modificado, Capsul $^{\circledR}$ ). 


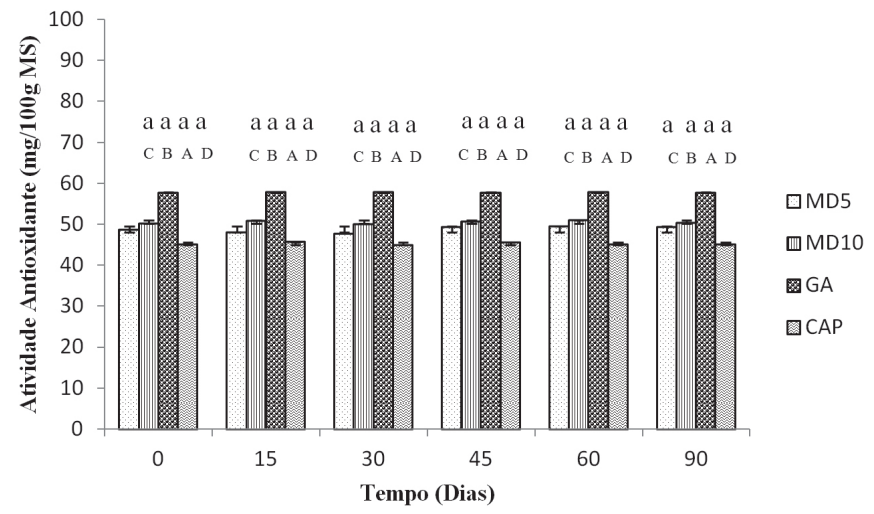

Figura 3. Evolução do teor de atividade antioxidante (TEAC) para amostras de morango em pó com os diferentes agentes carreadores ao longo do armazenamento a $25^{\circ} \mathrm{C}$. $(\mathrm{MD5}=$ Maltodextrina 5DE; MD10 = Maltodextrina 10DE; $\mathrm{GA}=$ Goma Arábica; CAP = Amido Modificado, Capsul $^{\circledR}$ ).

por sua vez, apresentaram diferença estatística entre si, em todos os tempos de armazenamento avaliados.

Letras minúsculas diferentes indicam diferença estatisticamente significativa para o mesmo agente carreador nos diferentes dias. Letras maiúsculas diferentes indicam diferença estatisticamente significativa entre diferentes materiais para o mesmo dia.

O maior valor de atividade antioxidante após o processo de secagem foi observado nas partículas produzidas com Goma Arábica, seguidas pelas amostras produzidas com Maltodextrina 10DE e Maltodextrina 5DE. As partículas produzidas com Capsul ${ }^{\circledR}$ apresentaram valor estatisticamente menor do que $\mathrm{p} \leq 0,05$.

Os resultados de atividade antioxidante seguiram a mesma tendência do teor de antocianinas, indicando que estes compostos são os principais responsáveis pela atividade antioxidante observada na polpa de morango.

Em relação à umidade, os diferentes agentes carreadores resultaram em valores significativamente diferentes logo após a secagem, enquanto que, após 90 dias de armazenamento, as amostras apresentaram valores de umidade maiores e mais próximos entre si (Tabela 7), indicando que a embalagem utilizada permitiu certa adsorção de água durante este período. Comportamento semelhante foi observado por Figueirêdo et al. (2001), que avaliaram a atomização de suco de acerola com maltodextrina e goma arábica, e o comportamento dos pós formados durante 360 dias.

Uma vez que a condição de armazenamento de todas as amostras foi a mesma, quanto menor a umidade inicial, maior o gradiente de concentração de água do ambiente para o produto, o que provavelmente proporcionou maiores taxas de transferência de massa, resultando, ao final de 90 dias, em valores de umidade próximos.
Tabela 7. Umidade das partículas produzidas com diferentes agentes carreadores.

\begin{tabular}{lcc}
\multicolumn{1}{c}{$\begin{array}{c}\text { Agentes } \\
\text { Carreadores }\end{array}$} & \multicolumn{2}{c}{ Umidade (\% B. U.) } \\
$\mathbf{1 .}^{\circ}$ Dia & $\mathbf{9 0 .}^{\circ}$ Dia \\
Maltodextrina 5DE & $2,27 \pm 0,06^{\mathrm{bB}}$ & $3,63 \pm 0,11^{\mathrm{bA}}$ \\
Maltodextrina 10DE & $1,85 \pm 0,02^{\mathrm{cB}}$ & $3,88 \pm 0,10^{\mathrm{abA}}$ \\
Goma Arábica $^{\text {Capsul }^{\circledR}}$ & $2,45 \pm 0,03^{\mathrm{aB}}$ & $4,13 \pm 0,10^{\mathrm{aA}}$ \\
\hline
\end{tabular}

Letras diferentes indicam diferença estatisticamente significativa a $p \leq 0,05$ : Letras minúsculas diferentes indicam diferença estatisticamente significativa entre os diferentes agentes carreadores para o mesmo dia. Letras maiúsculas diferentes indicam diferença estatisticamente significativa para o mesmo agente carreador nos diferentes dias.

\section{Conclusões}

Os quatro agentes carreadores avaliados (Maltodextrina 5DE, Maltodextrina 10DE, Goma arábica e Capsul $^{\circledR}$ ) foram adequados para a produção de uma polpa de morango em pó estável ao armazenamento.

Em relação às propriedades físicas, todas as amostras apresentaram solubilidade elevada, desejável para sucos de frutas em pó. A utilização dos quatro diferentes agentes carreadores resultou em pós com baixa umidade. Todas as amostras apresentaram isotermas de sorção do tipo III e foram mais adequadamente descritas pelo modelo de GAB. Os pós produzidos com a Maltodextrina 5DE e com a Goma arábica foram os menos higroscópicos. A polpa de morango desidratada com goma arábica apresentou o maior teor de antocianinas e, consequentemente, maior valor de atividade antioxidante, tanto imediatamente após a secagem como ao longo do armazenamento.

Do ponto de vista tecnológico, com base nos resultados obtidos no presente trabalho, a goma arábica pode ser indicada como o agente carreador mais adequado para a produção de polpa de morango em pó. Estudos adicionais sobre a viabilidade econômica do uso deste material devem ser ainda realizados.

\section{Agradecimentos}

À Coordenação de Aperfeiçoamento de Pessoal de Nível Superior - Capes, pela Bolsa concedida.

\section{Referências}

AGUILERA, M. J.; DEL VALLE, J. M.; KAREL, M. Caking phenomena in amorphous food powder. Trends in Food Science and Technology, Amsterdam, v. 6, n. 5, p. 149-155, 1995. http:// dx.doi.org/10.1016/S0924-2244(00)89023-8

AZEREDO, H. M. C. Encapsulação: aplicação à tecnologia de alimentos. Alimentos e Nutrição, Araraquara, v. 16, n. 1 , p. 89-97, 2005. 
Estabilidade da polpa de morango atomizada utilizando diferentes agentes carreadores OLIVEIRA, M. I. S. et al.

BARANAUSKIENÉ, R.; BYLAITÉ, E.; ZUKAUSKAITÉ, J.; VENSKUTONIS, R. P. Flavor Retention of peppermint (Mentha piperita L.) essential oil spray dryed in modified starches during encapsulation and storage. Journal of Agricultural and Food Chemistry, Chicago, v. 55, n. 8, p. 3027-3036, 2007. PMid:17381102. http://dx.doi.org/10.1021/jf062508c

BE MILLER, J. N.; WHISTLER, R. L. Carbohydrates. In: FENNEMA, O. R. (Ed.). Food Chemistry. New York: Marcel Dekker, 1996. cap. 4, p. 157-224.

BHANDARI, B. R.; DATA, N.; HOWES, T. Problems associated with spray drying of sugar-rich foods. Drying Technology, Philadelphia, v. 15, n. 2, p. 671-684, 1997. http://dx.doi. org/10.1080/07373939708917253

CAI, Y. Z.; CORKE, H. Production and properties of spraydried Amaranthus betacyanin pigments. Journal of Food Science, Malden, v. 65, n. 6, p. 1248-1252, 2000. http://dx.doi. org/10.1111/j.1365-2621.2000.tb10273.x

CANO-CHAUCA, M.; STRINGHETA, P. C.; RAMOS, A. M.; CAL-VIDAL, J. Effect of the carriers on the microstructure of mango powder obtained by spray drying and its functional characterization. Innovative Food Science and Emerging Technologies, Oxford, v. 5, n. 4, p. 420-428, 2005. http://dx.doi. org/10.1016/j.ifset.2005.05.003

CHARVE, J.; REINECCIUS, G. A. Encapsulation Performance of Proteins and Traditional Materials for Spray Dried Flavors. Journal of Agricultural and Food Chemistry, Chicago, v. 57, n. 6, p. 2486-2492. 2009. PMid:19231860. http://dx.doi. org/10.1021/jf803365t

DESOBRY, S. A.; NETTO, F. M.; LABUZA, T. P. Comparison of spray-drying, drum drying and freeze-drying for $\beta$-carotene encapsulation and preservation. Journal of Food Science, Malden, v. 62, n. 6, p. 1158-1162, 1997. http://dx.doi. org/10.1111/j.1365-2621.1997.tb12235.x

EASTMAN, J. E.; MOORE, C. O. Cold Water Soluble Granular Starch for Gelled Food Composition. U.S. Patent 4465702 , 14 ago. 1984.

ERSUS, S.; YURDAGEL, U. Microencapsulation of anthocyanin pigments of black carrot (Daucus carota L.) by spray dryer. Journal of Food Engineering, Oxford, v. 80, n. 3, p. 805-812, 2007. http://dx.doi.org/10.1016/j.jfoodeng.2006.07.009

FAGERLUND, G. Determination of specific surface by the BET method. Matériaux et Constructions, Paris, v. 6, n. 33, p. 239-245, 1973. http://dx.doi.org/10.1007/BF02479039

FENNEMA, O. R. Water and ice. In: FENNEMA, O. R. (Ed.). Food Chemistry. New York: Marcel Dekker, 1996, p. 17-94.

FERRARI, C. C.; GERMER, S. P. M.; ALVIM, I. D.; VISSOTTO, F. Z.; AGUIRRE, J. M. Influence of carrier agents on the physicochemical properties of blackberry powder produced by spray drying. International Journal of Food Science \&
Technology, Malden, v. 47, n. 6, p. 1237-1245, 2012. http:// dx.doi.org/10.1111/j.1365-2621.2012.02964.x

FIGUEIRÊDO, R. M. F.; GRANDIN, A.; MARTUCCI, E. T. Armazenamento do suco de acerola microencapsulado. Revista Brasileira de Produtos Agroindustriais, Campina Grande, v. 3, n. 1, p. 1-6, 2001.

GAL, S. Recent developments in techniques for obtaining complete sorption isotherms. In: ROCKLAND, L. B.; STEWART, G. E. (Eds.). Water activity: Influence on Food Quality. New York: Academic Press, 1981. p. 89-110. http://dx.doi.org/10.1016/ B978-0-12-591350-8.50009-7

GIUSTI, M. M.; WROLSTAD, R. E. Characterization and measurement of anthocyanins by UV-visible spectroscopy. In WROLSTAD, R. E. (Ed.). Current Protocols in Food Analytical Chemistry. New York: John Wiley \& Sons, Inc., 2001. cap. F1, p. F1.2.1-1.2.13

GOULA, A. M.; ADAMOPOULOS, K. G. Spray drying of tomato pulp: Effect of feed concentration. Drying Technology, Philadelphia, v. 22, n. 10, p. 2309-2330, 2004. http://dx. doi. org/10.1081/DRT-200040007

GREENSPAN, L. Humidity fixed points of binary saturated aqueous solutions. Journal of Research of the National Bureau of Standards - Physics and Chemistry, Washington, v. 81, n. 1, p. 89-96, 1977.

INSTITUTO ADOLFO LUTZ. Normas Analíticas: Métodos Químicos e Físicos para Análise de Alimentos. 3. ed. São Paulo: Instituto Adolfo Lutz, 2008. 1020p.

KLEWICKI, R.; KONOPACKA, D.; UCZCIWEK, M.; IRZYNIEC, Z.; PIASECKA, E.; BONAZZI, C. Sorption isotherms for osmo-convectively-dryed and osmo-freezedried apple, sour cherry and blackcurrant. Journal of Horticultural Science \& Biotechnology, Dundee, v. 84, n. 6, p. 75-79, 2009.

KUNTZ, L. A. Making the Most of Maltodextrins. Northbrook: Weeks Publishing Company, 1997. Disponível em: <http://www. foodproductdesign.com/articles/1997/08/making-the-most-ofmaltodextrins.aspx>. Acesso em 14 jun. 2013.

KUSKOSKI, E. M.; ASUERO, A. G.; MORALES, M. T.; FETT, R. Frutos troppicais silvestres e polpas de frutas congeladas: atividade antioxidante, polifenóis e antocianinas. Revista Ciência Rural, Santa Maria, v. 36, n. 4, p. 1283-1287, 2006. http://dx.doi.org/10.1590/S0103-84782006000400037

LOMAURO, C. J.; BAKSHI, A. S.; LABUZA, T. P. Evaluation of food moisture isotherm equations. 1: Fruit, vegetable and meat products. Lebensmittel-Wissenschaft und Technologie, Zurich, v. 18, n. 2, p. 111-117, 1985.

MOURA, R. S. F.; GOUVEIA, J. P. G.; ALMEIDA, F. A. C.; SOUSA, A. G.; SILVA, M. M.; OLIVEIRA, A. M. V. Modelagem matemática para isotermas em polpa de caju. Revista de Biologia e Ciência da Terra, João Pessoa, v. 4, n. 2, p. 32-40, 2004. 
Estabilidade da polpa de morango atomizada utilizando diferentes agentes carreadores

OLIVEIRA, M. I. S. et al.

OLIVEIRA, V. S.; AFONSO, M. R. A.; COSTA, J. M. C. Caracterização físico-química e comportamento higroscópico de sapoti liofilizado. Revista Ciência Agronômica, Fortaleza, v. 42, n. 2, p. 342-348, 2011. http://dx.doi.org/10.1590/S180666902011000200012

PAGLARINI, C. S.; SILVA, F.; PORTO, A. G.; PIASSON, D.; SANTOS, P. Histerese das isotermas de sorção da polpa de manga (Mangifera indica L.) variedade manteiga. Revista Brasileira de Engenharia Agrícola e Ambiental, Campo Grande, v. 17, n. 3, p. 299-305, 2013. http://dx.doi.org/10.1590/ S1415-43662013000300008

PARAMITA, V.; FURUTA, T.; YOSHII, H. High-Oil-Load Encapsulation of Medium-Chain Triglycerides and d-Limonene Mixture in Modified Starch by Spray Drying. Journal of Food Science, Malden, v. 77, n. 2, 2012.

RE, R.; PELLEGRINI, N.; PROTEGgente, A.; PANNALA, A.; YANG, M.; RICE-EVANS, C. Antioxidant Activity applying an improved ABTS radical cation decolorization assay. Free Radical Biology \& Medicine, New York, v. 26, n. 9-10, p. 1231-1237, 1999. http://dx.doi.org/10.1016/S0891-5849(98)00315-3

ROCHA, D. A.; ABREU, C. M. P.; CORRÊA, A. D.; SANTOS, C. D.; FONSECA, E. W. N. Análise comparativa de nutrientes funcionais em morangos de diferentes cultivares da região de Lavras-MG. Revista Brasileira de Fruticultura, Jaboticabal, v. 30 , n. 4, p. 1124-1128, 2008
ROOS, Y.; KAREL, M. Amorphous state and delayed ice formation in sucrose solutions. International Journal of Food Science \& Technology, Malden, v. 26, n. 6, p. 553-566, 1991. http://dx.doi.org/10.1111/j.1365-2621.1991.tb02001.x

SILVA, A. E.; SILVA, L. H. M.; PENA, R. S. Comportamento higroscópico do açaí e cupuaçu em pó. Ciência e Tecnologia dos Alimentos, Campinas, v. 28, n. 4, p. 895-901, 2008.

TONON, R. V.; BRABET, C.; HUBINGER, M. D. Anthocyanin stability and antioxidant activity of spray-dried açai (Euterpeoleraceae Mart.) juice produced with different carrier agents. Food Research International, Amsterdam, v. 43, p. 907-914, 2010. http://dx.doi.org/10.1016/j.foodres.2009.12.013

YOUSEFI, S.; EMAM-DJOMEH, Z.; MOUSAVI, M. S. Effect of carrier type and spray drying on the physicochemical properties of powdered and reconstituted pomegranate juice (Punica Granatum L.). Journal of Food Science and Technology, Mysore, v. 48, n. 6, p. 677-684, 2011. PMid:23572804 PMCid:PMC3551052. http://dx.doi.org/10.1007/s13197-0100195-X

ZHENG, Y.; WANG, S. Y.; WANG, C. Y.; ZHENG, W. Changes in strawberry phenolics, anthocyanins, and antioxidant capacity in response to high oxygen treatments. LWT - Food Science and Technology, Zurich, v. 40, n. 1, p. 49-57, 2007. 